\title{
ESTABELECIMENTO DE PEREIRA (Pyrus spp.) IN VITRO A PARTIR DE MERISTEMAS E GEMAS
}

\author{
IN VITRO ESTABLISHMENT OF PEAR (Pyrus spp.) \\ STARTING FROM MERISTEMS AND BUDS
}

\author{
Alan Cristiano Erig ${ }^{1}$ Gerson Renan de Luces Fortes ${ }^{2}$
}

\section{RESUMO}

O trabalho objetivou determinar o melhor tipo de explante e a melhor época de coleta destes, visando ao estabelecimento de cultivo in vitro da pereira. No experimento I, gemas e meristemas de pereira das cultivares Carrick e Garber foram isoladas 28 dias após o início da brotação das plantas matrizes. No experimento II, meristemas das cultivares Carrick, Garber e Smith foram isolados aos 28, 35, 42, 49 e 56 dias após o início da brotação. $O$ meio de cultura utilizado foi o MS,

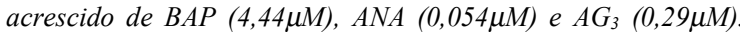
Após a inoculação, os explantes foram submetidos ao escuro sob temperatura de $25 \pm 2^{\circ} \mathrm{C}$ por um periodo de 4 dias e, em seguida, transferidos para sala de crescimento com 16 horas de fotoperíodo com radiação de $25 \mu$ moles. $m^{-2} . s^{-1}$ e temperatura de $25 \pm 2{ }^{\circ} \mathrm{C}$. Os resultados permitiram concluir que, para o estabelecimento in vitro da cultivar Carrick, foi possivel a utilização de gemas ou meristemas. Já para a cultivar Garber, o melhor explante foi o meristema; as épocas de isolamento dos meristemas mostraram comportamento linear para a percentagem de estabelecimento, obtendo-se $92,9 \%$ de estabelecimento nos meristemas isolados aos 56 dias após o início da brotação.

Palavras-chave: fruticultura, cultura de tecidos, Pyrus, meristemas, gemas, in vitro.

\section{SUMMARY}

The work had the purpose to determine the best type of explant and its best time of collection aiming to establish the in vitro culture for pear. In the first trial, pear buds and meristems from Carrick and Garber cultivars were isolated 28 days after the beginning of mother plants shooting. In the second trial, meristems from Carrick, Garber and Smith pear cultivars were isolated at 28, 35, 42, 49 and 56 days after shooting. The culture

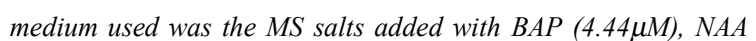
$(0.05 \mu \mathrm{M})$ and $\mathrm{GA}_{3}(0.29 \mu \mathrm{M})$. After the inoculation the explants were subjected to a dark room for four days at temperature $25 \pm$ $2^{\circ} \mathrm{C}$ and then transferred to a growth room in a 16 - hour photoperiod, $25 \mu \mathrm{moles} . \mathrm{m}^{-2} \cdot \mathrm{s}^{-1}$ radiation and at $25 \pm 2^{\circ} \mathrm{C}$. It could be concluded that: (i) for the in vitro establishment of the Carrick cultivar buds and meristems could be used, although for Garber $c v$., meristem is the best explant; and (ii) the time of meristem isolation showed a linear behavior to establish percentage achieving $92.9 \%$ for the meristems collected at 56 days after shooting.

Key words: horticulture; tissue culture; Pyrus; meristems; buds; in vitro.

\section{INTRODUÇÃO}

A escolha do explante apropriado constitui o primeiro passo para o estabelecimento dos cultivos in vitro (MROGINSKI \& ROCA, 1991). Diversos explantes podem ser utilizados para iniciar a propagação in vitro de uma planta. $\mathrm{Na}$ seleção destes, devem ser considerados aspectos como o nível de diferenciação do tecido utilizado e a finalidade da micropropagação (GRATTAPAGLIA \& MACHADO, 1998).

Teoricamente, qualquer tecido pode ser utilizado como explante, tendo em vista a totipotência das células vegetais (GRATTAPAGLIA \& MACHADO, 1998). Quando os explantes são de pequenas dimensões (cultivo de meristemas), a

\footnotetext{
${ }^{1}$ Engenheiro Agrônomo, Aluno do Programa de Pós-graduação em Agronomia, Área de Concentração Fruticultura de Clima Temperado, Faculdade de Agronomia Elizeu Maciel, Universidade Federal de Pelotas, CP 354, 90001-970, Pelotas, RS. E-mail: acerig@ufpel.tche.br. Autor para correspondência.

${ }^{2}$ Engenheiro Agrônomo, Doutor, Embrapa Clima Temperado, CP 403, Pelotas - RS. E-mail: gerson@cpact.embrapa.br.
} 
multiplicação geralmente visa eliminar viroses. O cultivo de ápices de maiores dimensões é empregado com o objetivo de multiplicação vegetativa quando a infecção por vírus não é um problema importante (MARGARA, 1988). Na maioria dos trabalhos envolvendo micropropagação de frutíferas, os explantes escolhidos geralmente são obtidos de gemas apicais ou axilares (FACHINELLO et al., 1995).

A idade do explante é um fator crítico para o estabelecimento in vitro de espécies lenhosas (Bong apud VILLALOBOS \& THORPE, 1991). Sabe-se que quanto mais novo e menos diferenciado o tecido a ser propagado, melhor será a resposta in vitro (Villalobos et al. apud VILLALOBOS \& THORPE, 1991).

Deve-se levar em consideração a incidência de outros fatores que também podem alterar as respostas dos explantes cultivados, entre estes, a época do ano em que se realizam os cultivos, especialmente quando os explantes são obtidos de plantas do campo (MROGINSKI \& ROCA, 1991). Em condições ambientais adversas, as plantas apresentam uma paralisação temporária de crescimento, num estado conhecido por dormência. Nessa condição, as exigências de termo e fotoperíodo para superar a dormência devem ser satisfeitas antes de utilizar a planta como fonte de explantes (TORRES $\boldsymbol{e t} \boldsymbol{a l}$., 1998).

A retirada dos explantes deve ser feita de preferência a partir de brotações novas que são formadas durante a fase ativa de crescimento da planta, após o final do período de dormência, durante os meses mais quentes do ano (GRATTAPAGLIA \& MACHADO, 1998). Contudo, mesmo que se tenha delimitado a idade do material, o melhor explante deve ser determinado experimentalmente (VILLALOBOS \& THORPE, 1991).

Através do presente trabalho, objetivou-se determinar o explante mais adequado e a época mais propícia para isolamento do meristema de plantas matrizes de pereira (Pyrus spp.), visando ao estabelecimento em cultivo in vitro.

\section{MATERIAL E MÉTODOS}

Os ensaios foram conduzidos no Laboratório de Cultura de Tecidos da Embrapa Clima Temperado, em Pelotas - RS, no ano de 2000.

No experimento I, no qual se testou o tipo de explante, gemas e meristemas de pereira das cultivares Carrick (P. communis L.) e Garber ( $\boldsymbol{P}$. communis X $\boldsymbol{P}$. pyrifolia), provenientes de brotações novas de plantas mantidas no campo, foram utilizados como explantes e constituíram os tratamentos. O tratamento gemas constituiu de gemas intactas, isto é, sem remoção das escamas, que foram isoladas dos segmentos nodais. As brotações novas das plantas matrizes, de onde foram isolados os meristemas e as gemas, foram coletadas 28 dias após o início da brotação.

No experimento II, foi avaliada a época de coleta de explantes para isolamento de meristemas. Os tratamentos consistiram em cinco diferentes épocas de isolamento do meristema após o período de dormência das plantas matrizes $(28,35$, 42, 49 e 56 dias, após o início da brotação). Meristemas de pereira das cultivares Carrick ( $\boldsymbol{P}$. communis L.), Garber (P. communis $\times$ P. pyrifolia) e Smith (P. communis x $\boldsymbol{P}$. pyrifolia), provenientes de brotações novas de plantas mantidas no campo, foram utilizados como explantes. Para diminuir a contaminação in vitro, as plantas matrizes do campo foram pulverizadas semanalmente com o antibiótico Agrimicina (Oxitetraciclina e Sulfato Estreptomicina - Pfizer) e o fungicida Dithane (Mancozeb) nas doses de $2,4 \mathrm{~g} \ell^{-1}$ e $1,0 \mathrm{~g} \ell^{-1}$, respectivamente. Em ambos os experimentos, as pulverizações iniciaram dez dias antes da primeira coleta.

As brotações novas coletadas no campo tiveram suas folhas removidas no ato da coleta, sendo desinfestadas no laboratório, posteriormente. O material coletado primeiramente foi imerso em álcool à $70 \%$ por 20 segundos para as gemas e 10 segundos para os meristemas e, em seguida, desinfectado com hipoclorito de sódio $2 \%$ por 15 minutos, adicionando uma gota de Tween 20. Na seqüência, o material desinfectado foi lavado três vezes com água destilada e autoclavada em câmara de fluxo laminar, para posterior isolamento dos explantes.

O meio de cultura utilizado foi o MS (MURASHIGE \& SKOOG, 1962), acrescido de $4,44 \mu \mathrm{M}$ BAP, $0,054 \mu \mathrm{M}$ ANA e $0,29 \mu \mathrm{M} \mathrm{AG}_{3}$, sendo o pH ajustado para 5,8 antes da inclusão do ágar na concentração de $6 \mathrm{~g} \cdot \ell^{-1} \mathrm{e}$, posteriormente, autoclavado a $121^{\circ} \mathrm{C}$ e $1,5 \mathrm{~atm}$ por 15 minutos. Foram utilizados tubos de ensaio $(150 \times 20 \mathrm{~mm}) \mathrm{com}$ $10 \mathrm{~m} \ell$ de meio de cultura.

Após a inoculação, os explantes foram mantidos em sala de crescimento no escuro, a $25 \pm$ $2^{\circ} \mathrm{C}$, por um período de quatro dias para diminuir a oxidação fenólica. Em seguida, foram transferidos para sala de crescimento com 16 horas de fotoperíodo com radiação de $25 \mu \mathrm{mo} \ell \mathrm{es} . \mathrm{m}^{-2} . \mathrm{s}^{-1} \mathrm{e}$ temperatura de $25 \pm 2^{\circ} \mathrm{C}$. 
Utilizou-se o delineamento experimental em blocos ao acaso, com 35 repetições por tratamento e um explante por tubo.

Após a inoculação foram realizadas avaliações da percentagem de contaminação aos 7 , 21 e 35 dias de cultivo, e de oxidação aos 21 e 35 dias de cultivo. As percentagens de sobrevivência e de estabelecimento foram avaliadas aos 45 dias de cultivo. A sobrevivência foi indicada pela coloração verde do explante (gema ou meristema). O estabelecimento foi determinado pelo desenvolvimento dos primórdios foliares nas gemas e pela presença de primórdios foliares visíveis nos meristemas. Os dados foram submetidos à análise de variância e as médias dos tratamentos comparadas estatisticamente pelo teste de Duncan ou analisados por regressão polinomial, através do uso do software SANEST (ZONTA \& MACHADO, 1987). Os dados em percentagens foram transformados em arco seno da raiz quadrada.

\section{RESULTADOS E DISCUSSÃO}

\section{Experimento I - tipo de explante}

A contaminação total (bacteriana mais fúngica) aos 7, 21 e 35 dias de cultivo, foi maior nas gemas, independentemente da cultivar (Figura 1). A contaminação bacteriana ocorreu até os sete dias de cultivo, com $45,7 \%$ de gemas e $18,8 \%$ de meristemas contaminados. A contaminação fúngica ocorreu somente nas gemas, onde alcançou 9,9\% e $11,5 \%$ aos 21 e 35 dias de cultivo, respectivamente. Estes resultados estão de acordo com TORRES $\boldsymbol{e t} \boldsymbol{a l}$. (1998), que afirma que, quanto menor o explante, maior a chance de se obter regenerantes isentos de contaminação. Segundo GRATTAPAGLIA \&
MACHADO (1998), considerando microrganismos contaminantes superficiais, o fato de levar menos tecido para condições assépticas reduz a quantidade desses microrganismos e aumenta a chance de sucesso de eliminar algum microrganismo.

Quanto à sobrevivência avaliada aos 45 dias de cultivo, observou-se que, na cultivar Carrick, não houve diferença significativa entre os explantes gemas e meristemas, enquanto na cultivar Garber, meristemas tiveram maior percentagem de sobrevivência (Figura 2). Com a utilização de gemas, houve diferença significativa de sobrevivência entre as cultivares, com $57,1 \%$ para a Carrick e 5,7\% para a Garber. A baixa sobrevivência das gemas da cultivar Garber deveu-se à formação de calo seguida de escurecimento provocado, possivelmente, pela quantidade de auxina no meio. Segundo GRATTAPAGLIA \& MACHADO (1998), quantidades excessivas de auxina estimulam a produção de calo. SMITH \& MURASHIGE (1970), sugerem que as zonas produtoras de auxinas não são propriamente os meristemas, e sim os primórdios foliares e as folhas em expansão, o que poderia explicar a razão pela qual a auxina não foi tão necessária na cultivar Garber, quando gemas foram utilizadas para o cultivo. Por outro lado, quando foram utilizados meristemas, não houve diferença significativa entre as cultivares quanto à sobrevivência, obtendo-se $85,7 \%$ na cv. Carrick e 71,4\% na cv. Garber (Figura 2). KIM et al. (1991) não obtiveram sucesso no cultivo inicial de meristemas de pereira cultivares Whangkeumbae, Chuwhangbae e Yeongsanbae em meio sólido; uma alta taxa de sobrevivência somente foi alcançada quando se utilizou meio líquido com uma ponte de papel filtro, dez dias antes do cultivo em meio sólido.

$$
\text { A percentagem de }
$$
estabelecimento avaliada aos 45 dias de cultivo, não diferiu significativamente entre gemas e meristemas para a cultivar Carrick. Já na cultivar Garber, o estabelecimento foi maior com a utilização de meristemas, o que está de acordo com BANNO et al. (1989) que, no estádio de estabelecimento de cultivo de Pyrus pyrifolia das cultivares Kosui, Hosui, Osa-nijisseiki e Yagumo, utilizaram ápices caulinares e obtiveram o melhor desenvolvimento e proliferação de brotações. Com gemas, obteve-se a maior percentagem de estabelecimento 


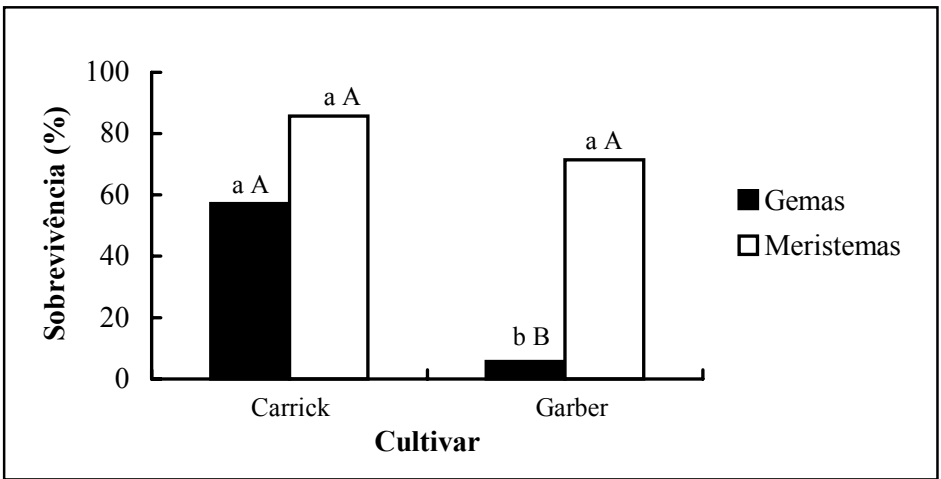

Figura 2 - Percentagem de sobrevivência em gemas e meristemas de pereira cvs. Carrick e Garber, aos 45 dias de cultivo. Pelotas/RS, 2000. Médias não seguidas de letra minúscula para mesma cultivar e maiúscula entre cultivares diferem pelo teste de Duncan em nível de 5\% de probabilidade de erro.

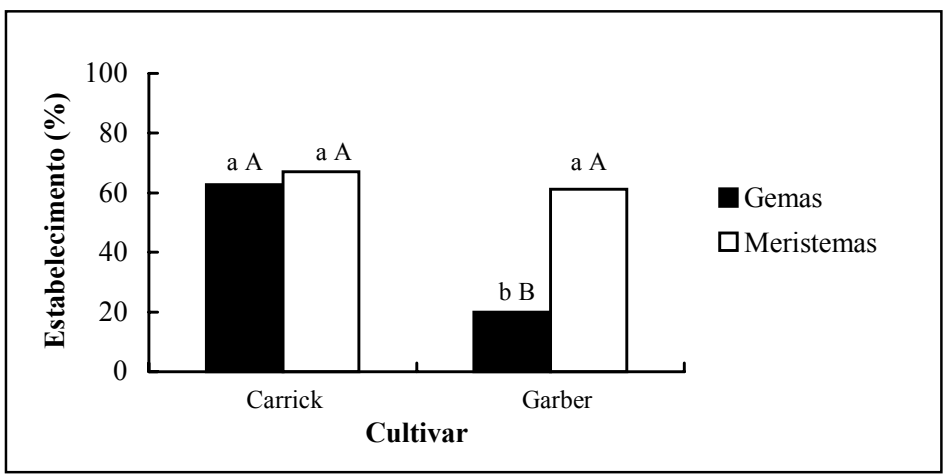

Figura 3 - Percentagem de estabelecimento de gemas e meristemas de pereira cvs. Carrick e Garber, aos 45 dias de cultivo. Pelotas/RS, 2000. Médias não seguidas de letra minúscula para mesma cultivar e maiúscula entre cultivares diferem pelo teste de Duncan em nível de 5\% de probabilidade de erro.

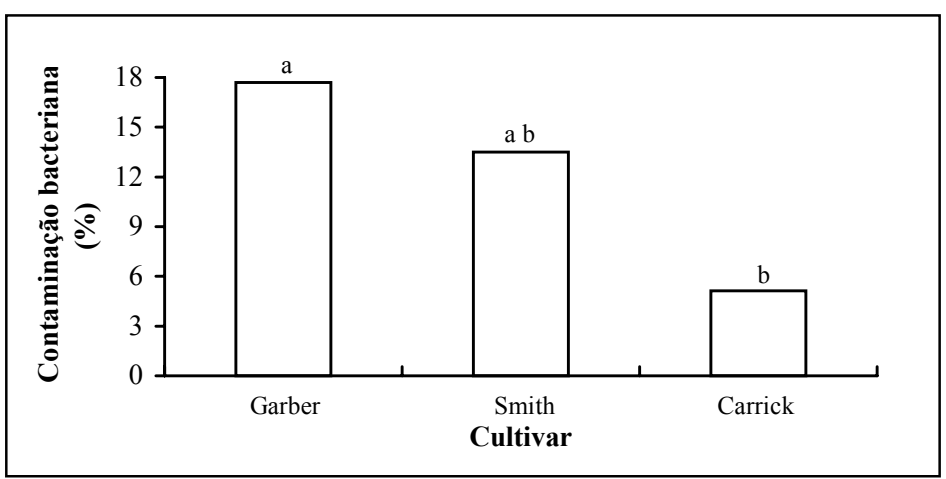

Figura 4 - Percentagem de contaminação bacteriana em meristemas de pereira cvs. Garber, Smith e Carrick, aos 7 dias de cultivo. Pelotas/RS, 2000. Médias não seguidas de mesma letra diferem pelo teste de Duncan em nível de $5 \%$ de probabilidade de erro.

na cultivar Carrick e, quando se utilizaram meristemas, não houve diferença significativa entre as cultivares (Figura 3).
Experimento II - época de coleta de explantes para isolamento de meristemas

Para a variável contaminação bacteriana, houve diferença significativa entre as cultivares, independente da época de isolamento dos meristemas, alcançando valores de $17,7 \%, 13,5 \%$ e $5,1 \%$ nas cultivares Garber, Smith e Carrick, respectivamente (Figura 4). Esta contaminação foi observada até sete dias de cultivo. A contaminação fúngica foi mais rara, pois só ocorreu após os 35 dias de cultivo. Segundo GRATTAPAGLIA \& MACHADO (1998), as contaminações bacterianas endógenas freqüentemente representam sério problema no estabelecimento das culturas. BUZCAN et al. (1997), isolando meristemas de gemas terminais e axilares de cerejeira doce coletadas na primavera, verão e outono, observaram que a contaminação bacteriana foi superior em meristemas coletados no verão.

A sobrevivência dos meristemas, avaliada aos 45 dias de cultivo, não apresentou diferença significativa entre as cultivares, bem como para as épocas de isolamento dos meristemas. Observou-se uma sobrevivência média de $83,6 \%$. BUZCAN et al. (1997) obtiveram o melhor resultado de sobrevivência de meristemas de cerejeira doce quando estes foram isolados na primavera, e a mais baixa sobrevivência quando estes foram isolados no outono. PEREZ-TORNERO et al. (1999a) observaram que, no início do inchamento da gema, ocorre a melhor época para isolar o meristema de damasqueiro da cultivar Canino.

$\mathrm{O}$ estabelecimento dos meristemas, avaliado aos 45 dias de cultivo, foi maior na cultivar Smith com $95,0 \%$ de estabelecimento, independentemente da época de isolamento. Para as cultivares Garber e Carrick não houve diferença significativa, com $84,3 \%$ e 75,4\%, respectivamente (Figura 5). BUZCAN et al. (1997) trabalhando com cerejeira doce cultivar Gi-Sel Al (P. fruticosa x $\boldsymbol{P}$. avium) não obtiveram proliferação a partir de meristemas. Neste caso, a maior parte dos explantes morreram 2 a 3 semanas após o estabelecimento. 
Observou-se comportamento linear das épocas de isolamento dos meristemas para a variável estabelecimento (Figura 6). Obtiveram-se $92,9 \%$ de estabelecimento dos meristemas quando estes foram isolados aos 56 dias após o início da brotação das plantas matrizes. PEREZ-TORNERO et al. (1999b) obtiveram resultado semelhante investigando o período ótimo para obtenção do meristema de damasqueiro (em relação à dormência), encontrando o melhor estádio, quando a gema vegetativa iniciava o crescimento.

\section{CONCLUSÕES}

Com os resultados obtidos nestes experimentos, conclui-se que, para o estabelecimento in vitro da cultivar Carrick, pode-se utilizar gemas ou meristemas, para a cultivar Garber, o melhor explante é o meristema; e os meristemas isolados aos 56 dias após o início da brotação apresentaram a maior percentagem de estabelecimento.

\section{REFERÊNCIAS BIBLIOGRÁFICAS}

BANNO, K., YOSHIDA, K., HAYASHI, S., et al. In vitro propagation of Japanese pear cultivars. Journal of the Japanese Society for Horticultural Science, Tokio, v. 58, n.1, p.3742, 1989.

BUZKAN, N., CETINER, S., YALCIN-MENDI, Y., et al. Clonal propagation of disease - free rootstocks for sour and sweet cherry by meristem culture. Acta Horticulturae, The Hague, n.441, p.329-332, 1997.

FACHINELLO, J.C., HOFFMANN, A., NACHTIGAL, J.C., $\boldsymbol{e}$ t al. Propagação de plantas frutíferas de clima temperado. 2.ed. Pelotas : UFPel, 1995. 179p.

GRATTAPAGLIA, D., MACHADO, M.A. Micropropagação. In: TORRES, A.C.; CALDAS, L.S., BUSO, J.A. ultura de tecidos e transformação genética de plantas. Brasília : Embrapa - SPI / Embrapa-CNPH, 1998. V.1, p.183-260.

KIM, T.C., SHIN, Y.U., HONG, K.H., et al. Studies on in vitro propagation of apical meristem in pear cultivars. Research Reports of the Rural Development Administration Biotechnology, Suweon, v.33, n.3, p.7-12, 1991.

MARGARA, J. Multiplicacion vegetativa y cultivo in vitro. Madrid : Mundi - Prensa, 1988. 232p.

MROGINSKI, L.A., ROCA, W.M. Establecimiento de cultivos de tejidos vegetales in vitro. In: ROCA, W.M., MROGINSKI, L.A. Cultivo de tejidos en la agricultura: Fundamentos y Aplicaciones. Cali, Colombia : CIAT (Centro Internacional de Agricultura Tropical), 1991. p.1940.

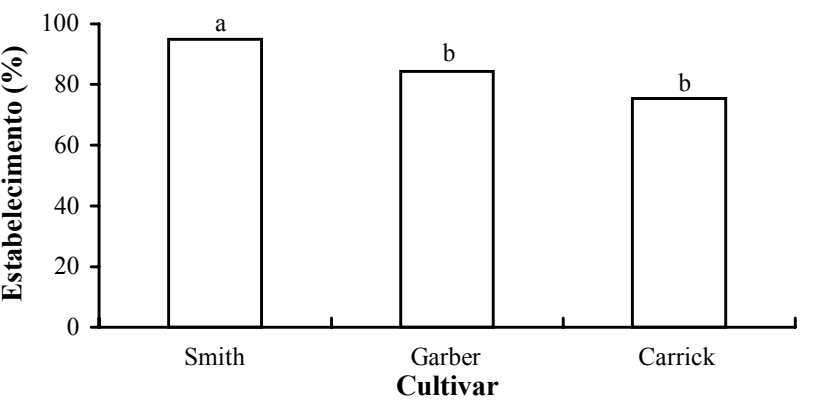

- Percentagem de estabelecimento de meristemas de pereira cvs. Smith, Garber e Carrick, aos 45 dias de cultivo, independentemente da época de isolamento. Pelotas/RS, 2000. Médias não seguidas de mesma letra, diferem pelo teste de Duncan em nível de 5\% de probabilidade de erro.

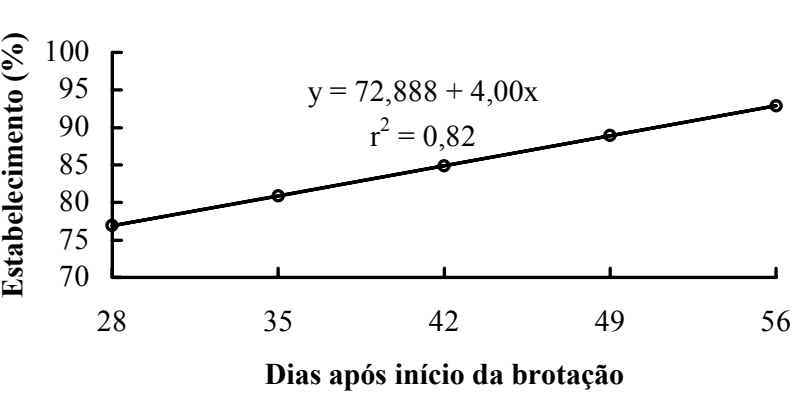

Figura 6 - Percentagem de estabelecimento de meristemas de pereira, independentemente da cultivar, aos 45 dias de cultivo, isolados aos $28,35,42$, 49 e 56 dias após o início da brotação. Pelotas/RS, 2000.

MURASHIGE, T., SKOOG, F. A revised medium for rapid growth and biossay with tobacco tissue cultures. Physiologia Plantarum, Kobenhavn, v.15, p.473-497, 1962.

PEREZ - TORNERO, O., BURGOS, L., EGEA, J. Introduction and establishment of apricot in vitro through regeneration of shoots from meristem tips. In vitro Cellular and Developmental Biology Plant, New York, v.35, n.3, p.249253, 1999a.

PEREZ - TORNERO, O., BURGOS, L., EGEA, J., et al. Apricot meristem tip culture. Acta Horticulturae, The Hague, n.488, p.411-416, 1999b.

SMITH, S.M., MURASHIGE, T. In vitro development of the isolated shoot apical meristem of angiosperms. American Journal of Botany, New York, v.57, p.562-568, 1970.

TORRES, A.C., TEIXEIRA, S.P., POZZER, L. Cultura de ápices caulinares e recuperação de plantas livres de vírus. In: TORRES, A.C., CALDAS, L.S., BUSO, J.A. Cultura de tecidos e transformação genética de plantas. Brasília: Embrapa - SPI / Embrapa - CNPH. 1998. v.1, p.133-145. 
VILLALOBOS A., V.M., THORPE, T.A. Micropropagación: conceptos, metodología y resultados. In: ROCA, W.M., MROGINSKI, L.A. Cultivo de tejidos en la agricultura: Fundamentos y Aplicaciones. Cali, Colombia : CIAT (Centro Internacional de Agricultura
Tropical), 1991, p.127-141.

ZONTA, E.P., MACHADO, A.A. SANEST - Sistema de análise estatística para microcomputadores. Pelotas : DMEC/IFM/UFPel, 1987. 138p. 